\title{
Venous emboli occur- ring during Caesarean section: the effect of patient position
}

The effect of position, horizontal versus $5^{\circ}$ reverse Trendelenburg's, on the incidence of venous emboli during Caesarean section was evaluated in 207 patients. Venous emboli were diagnosed using precordial ultrasonic Doppler monitoring. In the horizontal position, 44\% (60 of 134) parturients had venous emboli compared with $1 \%$ (1 of 73 ) parlurients in the $5^{\circ}$ reverse Trendelenburg's position ( $P<0.0001)$. Epidural anaesthesia was performed in 171 patients, and 36 patients had general anaesthesia. In the epidural group, pulse oximetric haenoglobin oxygen desaturation and complainls of chest pain andlor dyspnoea were associated with the venous emboli. Venous emboli, probably air, occur frequently during Caesarean section with the patient in the horizontal position. This occurrence was minimized by placing the patient in the $5^{\circ}$ reverse Trendelenburg's position.

$L^{\prime}$ effet de la position, horizontale versus Fowler de $5^{\circ}$ sur l'incidence de l'embolie veineuse lors d'une Césarienne fut évalué chez 207 patientes. L'embolie veineuse fut diagnostiquée utilisant une surveillance par Doppler ultrasonique précordial. En position horizontale, 44\% (60 de 134) parturientes avaient des embolies veineuses comparée à $1 \%$ (l sur 73) parturientes en position de Fowler de $5^{\circ}(P<0.0001)$. L'anesthésie épidurale fut faite chez 171 patientes, et 36 patientes ont reçu de l'anesthésie générale. Dans le groupe épidural, la saturométrie du pouls a démontré une désaturation el des

\section{Key words}

ANAESTHESIA: obstetric;

COMPLICATIONS: embolism;

EMBOLISM: air;

MEASUREMENT TECHNIQUES: Doppler ultrasound; SURGERY: Caesarean section.

From the Departments of Anesthesiology and Obstetrics \& Gynecology,* The New York Hospital:Cornell University Medical Center, New York, New York.

Address correspondence 10: Dr. Jill Fong, Department of Anesthesiology, The New York Hospital:Cornell University Medical Center, 525 East 68th Street, New York, NY 10021 Accepted for publication 24ih September, 1990. douleurs rétrosternales etlou la dysnée était associée avec l'embolie veineuse. L'embolie veineuse, probablement gazeuse, survient fréquemment lors d'une Césarienne chez les patientes en position horizontale. Cette fréquence fur diminuée en placant les patientes en position de Fowler de $5^{\circ}$.

Venous emboli have been detected during Caesarean section with regional and general anaesthesia using precordial ultrasonic Doppler monitoring. These venous emboli, probably air, have been associated with haemoglobin oxygen desaturation and chest pain and/or dyspnoea. 1,2 During any surgical procedure venous air embolism can occur if the operative field is above the level of the heart. ${ }^{3}$ Therefore, raising the level of the heart above the operative site should decrease the incidence of air entrainment. However, Karuparthy et al. found that the use of a flexed 5 to $10^{\circ}$ head-up tilt did not decrease their incidence of venous embolism. ${ }^{4}$

In this study, the incidence of venous emboli by Doppler monitoring during Caesarean section was compared with patients in the horizontal versus the $5^{\circ}$ reverse Trendelenburg's position. Associated changes in haemoglobin oxygen saturation, measured by pulse oximetry, and unsolicited parturient complaints of chest pain and/or dyspnoea were recorded.

\section{Methods}

With approval from the institution's Human Rights Committee and parturient informed consent, 207 ASA physical status I or II parturients undergoing Caesarean section with lumbar epidural or general anaesthesia were studied prospectively in a sequential manner with precordial ultrasonic Doppler monitoring. The first group of patients was placed in the horizontal position (Group A) and the next group in the $5^{\circ}$ reverse Trendelenburg's position (Group B). Under epidural anaesthesia, 110 parturients were monitored in the horizontal position and 61 in the $5^{\circ}$ reverse Trendelenburg's position. Under general anaesthesia, there were 24 parturients in the horizontal position and 12 in the $5^{\circ}$ reverse Trendelenburg's position. 
With the patient breathing room air, lumbar epidural anaesthesia was induced using either bupivacaine, lidocaine or 2-chloroprocaine. Sensory blockade to pin prick was maintained at the fourth thoracic dermatome level throughout the Caesarean section.

General anaesthesia consisted of a rapid sequence induction with thiopentone and succinylcholine followed by maintenance with $50 \%$ oxygen:50\% nitrous oxide and $0.75 \%$ enflurane. After delivery of the baby, the parturient inhaled a $30 \%$ oxygen: $70 \%$ nitrous oxide mixture and received intravenous fentanyl, droperidol and a succinylcholine infusion. The lungs were mechanically ventilated with positive pressure and zero end expiratory pressure.

All parturients were supine with left uterine displacement. Maternal blood pressure was maintained within $20 \%$ of its pre-anaesthetic level using iv Ringer's lactate (RL) and ephedrine sulfate. Supplemental oxygen was given if the parturient's oxygen saturation decreased to 93\%. None of the parturients received transfusion of blood products. They all received an iv oxytocin infusion (20 units $\cdot L^{-1} R L$ ) immediately after the delivery of the placenta. Intravenous fluids and drugs were administered through Abbott Hemosets (8948) to prevent accidental infusion of air.

Patients were monitored with an automatic blood pressure cuff (Physio-Control VSM 2), electrocardiogram, liquid crystal skin temperature sticker (Clinitemp, Inc.), Foley catheter, neuromuscular stimulator (general anaesthesia patients only) and finger pulse oximetry (Nellcor). Pulse oximetric haemoglobin desaturations were recorded and defined as a decrease from $>97 \%$ to $<95 \%$ which lasted more than one minute; the margin of error of the pulse oximeter is reported by the manufacturer to be $2 \% .^{2}$ All unsolicited complaints of chest pain and/or dyspnoea were recorded.

A precordial ultrasonic Doppler (Medasonics Versatone D8) was placed parasternally over the fourth right intercostal space. The correct placement of the Doppler transducer was confirmed by giving a rapidly injected 5 $\mathrm{ml}$ bolus of crystalloid solution through the most proximal port of the patient's peripheral intravenous line. ${ }^{5}$ During the Caesarean section, a Doppler change consistent with venous embolism was defined as a chirping to broken-up roaring change in the rhythmic swishing sound of the normal Doppler signal that lasted more than five seconds. ${ }^{6,7}$ Doppler monitoring began immediately before the beginning of the Caesarean section and finished immediately after skin closure at the end of surgery.

Data were analyzed using Chi square analysis with Yates' correction or two-tailed Fisher exact test to determine the relationship between categorical variables. Comparisons of measured variables were made using the Mann-Whitney non-parametric test. Multiple linear logis-
TABLE I Demographic variables

I Age
2 Height
3 Weight
4 Gravity
5 Parity
6 Reason for Caesarean section
7 Incidence of active labour
8 Volume of preoperative iv fluids
9 Type of local anaesthetic
10 Baseline systolic and diastolic blood pressure
11 Baseline pulse rate
12 Volume of intraoperative iv fluids
13 Method of placenta removal
14 Use of iv ephedrine
15 Incidence of intraoperative hypotension
16 Operative time
17 Estimated blood loss
18 Apgar scores

tic regression was used to analyze the incidence of emboli as a function of maternal position after adjusting for other potentially confounding variables. $P<0.05$ was considered statistically significant.

\section{Results}

There were no significant differences between Groups A and $B$ with respect to the demographic variables listed in Table I except for the method of placenta removal (passive removal occurred more frequently than manual removal in Group $A$ ), the amount of intraoperative fluids (Group A received $1751.64 \pm 467.95 \mathrm{ml}$ while Group B received $1855.48 \pm 353.90 \mathrm{ml}(P<0.05))$ and the local anaesthetic used (bupivacaine was given more frequently to Group B). The demographic data in parturients receiving general versus epidural anaesthesia were comparable except that those with epidurals received significantly more preoperative fluids, intraoperative fluids and iv ephedrine, and had lower systolic and diastolic blood pressures. The demographic data in patients with and without emboli and in patients receiving different local anaesthetics were not statistically different.

Using precordial ultrasonic Doppler monitoring, the incidence of venous emboli in Group A was 50\% (12 of 24) during general anaesthesia and $44 \%$ (48 of 110 ) during epidural anaesthesia. In Group B, the incidence of venous emboli was $0 \%$ ( 0 of 61 ) during epidural anaesthesia and $8 \%$ ( 1 of 12) during general anaesthesia. After accounting for the confounding demographic variables, multivariate logistic regression showed that there was a statistically significant difference between the incidence of venous emboli in Group A versus Group B $(P<0.0001)$. The incidence of venous embolism was greater in Group $A$ than in Group B. No statistical difference existed between 
TABLE II Association of haemoglobin oxygen desaturation with venous embolism in epidural anaesthesia patients

\begin{tabular}{lrr}
\hline & \multicolumn{2}{c}{ Venous embolism } \\
\cline { 2 - 3 } & Yes & No \\
\hline Oxygen desaturation & & \\
Yes & 4 & 0 \\
No & 44 & 123 \\
\hline
\end{tabular}

$P<0.01$

TABLE III Association of chesI pains and/or dyspnoea with venous embolism in epidural anaesthesia patients

\begin{tabular}{|c|c|c|}
\hline & \multicolumn{2}{|c|}{ Venous embolism } \\
\hline & Yes & No \\
\hline \multicolumn{3}{|c|}{ Symptoms } \\
\hline Yes & 9 & 3 \\
\hline No & 39 & 120 \\
\hline
\end{tabular}

$P<0.01$

the incidence of venous emboli detected during general versus epidural anaesthesia.

In Group A, embolism sometimes occurred more than once during a Caesarean section and occurred at any time. Regardless of the anaesthetic technique the relationship between embolic and surgical events were: $18 \%$ before uterine incision, $22 \%$ with uterine incision, $5 \%$ with delivery of the baby, $28 \%$ with placenta removal, $33 \%$ with uterine repair and $10 \%$ after uterine repair.

In the epidural anaesthesia group, transient oxygen desaturation (defined as a decrease from greater than $97 \%$ to less than $95 \%$ haemoglobin oxygen saturation which lasted more than one minute) was associated with these emboli in $8.3 \%$ of parturients who had emboli (Table II). Chest pain and/or dyspnoea were significantly associated with venous embolism in this group (Table III).

In one patient, the venous embolism produced haemodynamic compromise. Under epidural anaesthesia and in the horizontal position, this embolism occurred shortly after skin incision while the surgeon was still working in the superficial subcutaneous tissue. It manifested as chest pain, dyspnoea, ventricular tachycardia, hypotension and a decrease in haemoglobin oxygen saturation from 100 to $74 \%$ measured by pulse oximetry and arterial gas measurements. 8

Although $15.4 \%$ of the parturients who experienced emboli during general anaesthesia had a decrease in oxygen saturation, it was not statistically significant; two of 13 patients with emboli had desaturations versus zero of 23 patients without emboli. There was no correlation
TABLE IV Association of method of placenta removal and hysterolomy repair with venous emboli

\begin{tabular}{lrr}
\hline & \multicolumn{2}{l}{ Venous embolisin } \\
\cline { 2 - 3 } & Yes & No \\
\hline Method of placenta removal & 51 & 127 \\
Manual extraction & 10 & 19 \\
Passive separation & 58 & 139 \\
Method of hysterotomy repair & 3 & 7 \\
Uterus exteriorized & & \\
Uterus not exteriorized & & \\
\hline
\end{tabular}

between chest pain and/or dyspnoea and haemoglobin oxygen desaturation. Premature ventricular contractions ( 1 of 207) were not associated with these emboli. Neither manual extraction or passive separation of the placenta or exteriorization of the uterus for repair were significantly associated with emboli (Table IV).

Patients with placenta praevia (one of four) had no increased incidence of embolism. However, the one incident of venous embolism detected in the $5^{\circ}$ reverse Trendelenburg's position occurred with uterine incision and delivery of the neonate in a parturient with a complete placenta praevia.

\section{Discussion}

Our study found the incidence of venous emboli to be $50 \%$ and $44 \%$ in horizontally positioned patients receiving general or epidural anaesthesia, respectively. These emboli occurred at any time during Caesarean section. With the patient in the horizontal position with left uterine displacement, Doppler-detected venous emboli have been reported with varying incidence during Caesarean section. Differences in the embolism incidence and timing between our study and other studies may be due to the differing criteria used to define a positive Doppler change. In our study, a Doppler change consistent with venous embolus was a signal change that lasted for at least five seconds. This criteria was chosen because Maroon $e t$ al. found that small amounts of air could produce a readily detectable change in Doppler signal lasting three to five seconds; the more air injected led to a more prolonged Doppler signal change. ${ }^{6.7}$ Malinow et al., Vartikar et al. and Karuparthy et al. found a 52,65 and $11 \%$ incidence of Doppler-detected venous embolism, respectively. . $2,4^{2,4}$ The emboli occurred with hysterotomy, delivery of the baby, placenta delivery and hysterotomy repair. Malinow et al. and Karuparthy et al. defined a Doppler change consistent with venous embolus as lasting at least 15 seconds. Based on the differing Doppler criteria, it is not surprising that our study reports a higher incidence of venous embolism than Karuparthy et al. 
Theoretically, by elevating the parturient's heart above the operative site and increasing venous pressure, the possibility of the venous entrainment of air should be decreased or eliminated. However, Karuparthy et al. found that the 5 to $10^{\circ}$ head-up tilt position did not decrease the incidence of venous emboli. ${ }^{4}$ In our study, the $5^{\circ}$ reverse Trendelenburg's compared with the horizontal position produced a significant decrease in the incidence of embolic events in patients given general or epidural anaesthesia. This difference may be attributable to both the different positions used and the different criteria used to define a positive Doppler change. In this study, the entire operating table was tilted $5^{\circ}$ head-up versus the table being flexed $5-10^{\circ}$ head-up in Karuparthy's study. Perhaps the flexed position led to a decreased venous return, and thus decreased venous pressure, due to compression of the parturient's femoral veins. This might have been able to offset the potential benefits of the flexed head-up position.

It is difficult to blind a study such as this because an investigator was part of the operating room team and could clearly see if the patient was in the horizontal or $5^{\circ}$ reverse Trendelenburg position. However, every Caesarean section was attended by both an investigator, who may have had some bias, and a senior anaesthesia resident, who had no bias since they were not privy to the study design. Both the investigator and the resident present concurred on the occurrence of a Doppler change consistent with venous embolism.

Both Malinow et al. ${ }^{1}$ and Vartikar et al. ${ }^{2}$ found that chest pain and/or dyspnoea were associated with venous emboli. Vartikar et al. reported that decreases of $\geq 3 \%$ in pulse oximetric haemoglobin oxygen saturations were associated with Doppler-detected venous emboli and that oxygen desaturations were associated with maternal symptoms. ${ }^{2}$ Our study used different criteria to define haemoglobin oxygen desaturation: $>97 \%$ to $<95 \%$. In the epidural anaesthesia group, maternal symptoms and asymptomatic haemoglobin oxygen desaturation were associated with emboli. but not with each other. In the general anaesthesia group, haemoglobin oxygen desaturation was not significantly associated with emboli probably due to the small sample size. It should be noted that patients who received epidural anaesthesia were breathing $21 \%$ oxygen while those who had general anaesthesia received $30-50 \%$ oxygen. No supplemental oxygen was given to patients who received epidural anaesthesia so that changes in maternal oxygenation in association with emboli could be determined. In general, before delivery of the baby, maternal oxygen should be supplemented, and patients with oxygen desaturations associated with venous emboli should receive $100 \%$ oxygen.

Despite a difference in demographic data, patients receiving general versus epidural anaesthesia had similar incidences of emboli. The reason is unclear but is probably due to a combination of offsetting factors which lead to similar incidences of intraoperative hypotension. The use of positive pressure ventilation with zero end expiratory pressure versus spontaneous, negative pressure ventilation might be expected to decrease the incidence of emboli in the general anaesthesia group, but this did not turn out to be the case.

Despite the high incidence of venous emboli during Caesarean section in patients in the horizontal position, haemodynamically important venous air embolism is rare and recognizable risk factors are lacking. Durant et al. and Younker et al. suggest that patients with severe hypovolaemia, abruptio placenta, placenta praevia or manual placenta separation are at high risk for having venous air embolism. ${ }^{3,9}$ However, our results showed no increased incidence of embolism associated with placenta praevia or the method of placental separation. Furthermore, the incidence of haemodynamically compromising venous air embolism in this series was $0.7 \%$, and this event occurred in a parturient who did not fall into any recognized high-risk category. ${ }^{8}$ Because of the rarity of serious haemodynamic aberrations and the lack of definitive risk factors, there are varying viewpoints regarding which patients undergoing Caesarean section should be monitored with precordial ultrasonic Doppler. ${ }^{3,10-13}$

In conclusion, using precordial Doppler monitoring, venous emboli, probably air, occur frequently in parturients in the horizontal position during Caesarean section under epidural or general anaesthesia. This occurrence was minimized by placing the patient in the $5^{\circ}$ reverse Trendelenburg's position. Regardless of whether or not one chooses to monitor the parturient undergoing Caesarean section with a precordial Doppler, we feel that she should be placed in the $5^{\circ}$ reverse Trendelenburg's position with left uterine displacement unless there is some medical contraindication. Additionally, the possibility of venous air embolism should be high in the differential diagnosis of sudden cardiopulmonary instability during Caesarean section.

\section{References}

1 Malinow AM, Naulty JS, Hum CO, Datta S, Ostheimer $G W$. Precordial ultrasonic monitoring during Cesarean delivery. Anesthesiology 1987; 66: 816-9.

2 Vartikar JV, Johnson MD, Datta S. Precordial Doppler monitoring and pulse oximetry during Cesarean delivery: detection of venous air embolism. Regional Anesthesia 1989; 14: 145-8.

3 Younker D, Rodriguez V, Kavanagh J. Massive air embolism during Cesarean section. Anesthesiology 1986; 65: 77-9. 
4 Karuparthy VR, Downing JW, Husain FJ et al. Incidence of venous air embolism during Cesarean section is unchanged by the use of a $51010^{\circ}$ head-up tilt. Anesth Analg 1989; 69: 620-3.

5 Naulty JS, Ostheimer GW, Datra S, Knapp R, Weiss $J B$. Incidence of venous air embolism during epidural catheter insertion. Anesthesiology 1982; 57: 410-2.

6 Maroon JC, Goodman JM, Horner TG, Campbell $R L$. Detection of minute venous air emboli with ultrasound. Surg Gynecol Obstet 1968; 127: 1236-8.

7 Maroon JC, Edmonds-Seal J, Campbell RL. An ultrasonic method for detecting air embolism. J Neurosurg 1969; 31: 196-201.

8 Fong J, Gadalla F, Antonacci Gimbel A. Precordial Doppler diagnosis of haemodynamically compromising air embolism during Caesarean section. Can J Anaesth 1990; 37: 262-4.

9 Durant TM, Long J, Oppenheimer MJ. Pulmonary (venous) air embolism. Am Heart J 1947; 33: 269-81.

10 Martland HS. Air embolism. Am J Surg 1945; 68: 281-6.

11 Robinson DA, Albin $M S$. Venous air embolism and Cesarean sections. Anesthesiology 1987; 66: 93-4.

12 Rupp SM. Central venous pressure monitoring during Cesarean section. Anesthesiology 1987; 67: 146-7.

13 Robinson DA, Bunegin L, Albin MS. Reply to: Central venous pressure monitoring during Cesarean section. Anesthesiology 1987; 67: 147-8. 